\title{
Editorial
}

\section{These ever changing times}

Those of you who attended the annual meeting in Surrey this year will know that important changes are underway within the Proceedings. From the Summer Meeting 2009 onwards, abstracts will no longer be edited at the meetings and instead will move to a one-stage accept or reject procedure with accepted abstracts being copy edited by Cambridge Journals before publishing. Whilst I accept that the Society needs to 'move with the times' in streamlining how it deals with abstracts from offered contributions, on a personal level I will miss the interaction with members in terms of what have always been very enjoyable discussions concerning their work. I truly hope that we will be able to maintain the close linkage that has existed between the Society membership and the editorial team within the Proceedings.

Also, from early next year an Editorial Board for Proceedings of the Nutrition Society will be established to improve the handling of submitted manuscripts. I believe this development is vital if we are to continue to drive forward the impact and relevance of the journal. Whilst accepting the numerous caveats associated with the use of impact factors as an indicator of publication quality, or even impact, it is highly rewarding that again this year the impact factor of the Proceedings has risen (to 3.981), making it the 6th highest cited journal within the Nutrition and Dietetics classification of the Thomson Reuters Science Citation Index. A balanced Editorial Board capable of expert review of the wide range of papers published in the journal is vital if we are to maintain and indeed enhance this position. To this extent it is proposed that the Editorial
Board will consist of:

An Editor-in-Chief who would retain control of the journal on behalf of the Society

Two Deputy Editors

An Editorial Board of no more than five as selected by the Editors

Indeed, as I write, a call for volunteers to help populate this Editorial Board and drive the journal forward is on the Society's web pages and I am sure this will invoke an enthusiastic response from the membership.

On a more personal level, my own term of office as Editor of the Proceedings has now come to an end. It has been an honour to serve in this capacity and I know I cannot stand down without acknowledging the work of the staff within the Nutrition Society office who have done so much to put the Journal together during my editorship: in particular, Asha Thiruchelvam, Catherine Jackson and Hajnal Zdravics. However, I must especially acknowledge the role of Dr Christine Hughes, who as Sub-editor is, in a very real sense, the true editor of the Proceedings. Christine will also be moving on to another role in the Society and I believe it is fitting that I highlight her pivotal role in the success of the Proceedings. Lastly, the Society is not quite free from me as I have agreed to stay on for 1 year in the role of Deputy Editor to help our new Editor-in-Chief Professor Klaas R. Westerterp establish the Editorial Board. As a result, I will still be around at Society meetings and look forward to meeting members again. Perhaps we could even discuss your abstracts! 